\title{
Componentes produtivos do trigo afetados pela densidade de semeadura e aplicação de regulador vegetal
}

\author{
Yield components in wheat affected by sowing density \\ and growth regulators
}

\author{
Samuel Luiz Fioreze ${ }^{1 *}$; João Domingos Rodrigues ${ }^{2}$
}

\begin{abstract}
Resumo
Melhorar as características produtivas de plantas cultivadas através de práticas de cultivo é um dos principais desafios da pesquisa frente à crescente demanda de alimentos em nível mundial. O presente trabalho teve por objetivo estudar as características morfofisiológicas e suas relações com os componentes da produção e a produtividade da cultura trigo em função da densidade de semeadura e da aplicação de reguladores vegetais. O experimento de campo foi conduzido em delineamento experimental de blocos casualizados em esquema de parcelas sub-divididas com quatro repetições. As parcelas foram formadas por quatro densidades de semeadura (30, 50, 70 e 90 plantas $\left.\mathrm{m}^{-1}\right)$ enquanto as sub-parcelas foram formadas pela aplicação de reguladores vegetais [controle, (IBA+GA+KT), Etil-Trinexapac e $(\mathrm{IBA}+\mathrm{GA}+\mathrm{KT})+$ Etil-Trinexapac]. Foram avaliados o acúmulo de matéria seca, a altura de plantas, a distância entre fonte e dreno, as trocas gasosas e a produtividade da cultura. A aplicação de EtilTrinexapac resultou em diminuição da altura de plantas, da distância fonte-dreno e do desenvolvimento da folha bandeira, sem afetar a produtividade da cultura. A densidade de semeadura afetou o acúmulo de matéria seca de plantas, sendo que o maior acúmulo de matéria seca na fase de antese teve efeito positivo direto nos componentes da produção e na produtividade da cultura nas menores densidades.
\end{abstract}

Palavras-chave: Triticum aestivum L., perfilhamento, acúmulo de matéria seca, folha bandeira, $\mathrm{IBA}+\mathrm{GA}+\mathrm{KT}$, Etil-Trinexapac

\begin{abstract}
Improvement on yield potential of plants by crop management is the main research challenge due to the growing of food demand worldwide. The objective of this work was to study physiological and morphological traits and its relationship with yield components and yield of wheat as affected by sowing densities and plant growth regulators. The experimental design was a split-plot design with four replications. The plots were consisted by four sowing densities (30, 5070 and 90 plants $\left.\mathrm{m}^{-1}\right)$ and the subplots were consisted by plant growth regulators [control, (IBA+GA+KT), Trinexapac-Ethyl e $(\mathrm{IBA}+\mathrm{GA}+\mathrm{KT})+$ Trinexapac-Ethyl]. Dry matter accumulation, plant height, source-sink distance, gas exchange and yield were determined. Trinexapac-Ethyl application resulted in decreasing of plant height, source-sink distance and flag leaf length; however, the grain yield was not affected. The number of plants per unit area affected dry matter accumulation. Higher dry matter accumulation showed direct relationship with yield and yield components in lower plant densities.

Key words: Triticum aestivum L., tillering, dry matter accumulation, flag leaf, IBA+GA+KT, Trinexapac-Ethyl
\end{abstract}

${ }^{1}$ Eng $^{\circ}$ Agr $^{\circ}$, Prof. Auxiliar, Universidade Federal de Santa Catarina, UFSC, Dept ${ }^{\circ}$ de Ciências Agronômicas, Curso de Agronomia, Curitibanos, SC. E-mail: s.fioreze@ufsc.br

${ }^{2}$ Eng $^{\mathrm{o}} \mathrm{Agr}^{\mathrm{o}}$, Prof. Titular, Universidade Estadual Paulista Júlio de Mesquita Filho, UNESP, Dept ${ }^{\circ}$ de Botânica, Instituto de Biociências. Distrito de Rubião Júnior, Botucatu, SP. E-mail: mingo@ibb.unesp.br

* Autor para correspondência 


\section{Introdução}

A produtividade final de uma cultura é uma característica quantitativa complexa, relacionada com a habilidade da planta em produzir, translocar e estocar carboidratos nos grãos (SLEEPER; POELMAN, 2006). Os produtos da fotossíntese elaborados nas folhas situadas na porção superior do colmo (principalmente a folha bandeira) e nas aristas são responsáveis pela maior parte da produção, enquanto as folhas inferiores contribuem com 15 a $20 \%$ do total de rendimento de grãos (DOMICIANO et al., 2009). Contudo, reservas do colmo acumuladas na planta até a pré-antese estão sendo crescentemente reconhecidas como importante fonte de carbono para enchimento do grão quando a fotossíntese é inibida por estresse hídrico, por calor ou por doenças (ASSENG; VAN HERWAARDEN, 2003). As duas características ocorrem em diferentes materiais e são de grande importância para a produção de grãos, principalmente, em regiões sujeitas a ocorrência de déficit hídrico (INOUE et al., 2004).

A densidade de semeadura é considerada uma das técnicas culturais que mais influenciam o rendimento de grãos e seus componentes, assim como o manejo da adubação e de épocas de semeadura (OZTURK; CAGLAR; BULUT, 2006). A elevada capacidade de compensar a falta ou excesso de um componente do rendimento através da modificação dos demais componentes (HOLEN et al., 2001) proporciona à cultura do trigo apresentar comportamento produtivo relativamente constante em condições variadas de cultivo. A densidade de semeadura pode afetar a produção final da cultura através dos seus efeitos na emissão e sobrevivência de perfilhos, na capacidade de adaptar sua estrutura em termos de arquitetura de plantas, a fim de manter a eficiência na utilização da radiação, principalmente pela folha bandeira (CRUZ et al., 2003). Desta forma, mudanças na densidade de semeadura têm importância especial na cultura do trigo, pois exercem efeitos diretos no número de espigas e no rendimento individual de espigas das plantas (OZTURK; CAGLAR; BULUT, 2006).
O balanço hormonal apresenta relação direta com o potencial produtivo da cultura, pois define a expressão fenotípica de plantas em função da disponibilidade de recursos no ambiente de cultivo. $\mathrm{Na}$ cultura do trigo, o balanço entre auxinas e citocininas é determinante para emissão de perfilhos, tendo efeito direto sobre a definição dos componentes da produção de grãos (VALÉRIO et al., 2009). Posteriormente, o aumento na atividade endógena de giberelinas, resulta no alongamento dos entrenós do colmo (ARTECA, 1995; TAIZ; ZEIGER, 2009), afetando a capacidade de acúmulo de reservas e a resistência ao acamamento de plantas (CRUZ et al., 2001). O balanço endógeno entre hormônios promotores e inibidores do crescimento pode ser resultado das condições do ambiente, como adubação, densidade de semeadura, entre outros, ou mesmo da aplicação de reguladores de crescimento, a fim de manejar o desenvolvimento da cultura.

Os efeitos fisiológicos de reguladores vegetais têm sido estudados visando o avanço no conhecimento da ação estimulatória ou inibitória no crescimento e desenvolvimento das plantas (MARTINS; CASTRO, 1999). Contudo, a validação do uso deste tipo de reguladores como prática de manejo deve passar ainda por estudos aprofundados das características morfofisiológicas e da produtividade de culturas. Neste contexto, o presente trabalho teve por objetivo estudar as características morfofisiológicas e suas relações com a produtividade da cultura trigo em função da densidade de semeadura e da aplicação de reguladores vegetais.

\section{Material e Métodos}

O experimento de campo foi conduzido no período de abril a agosto de 2010 em Botucatu (SP),

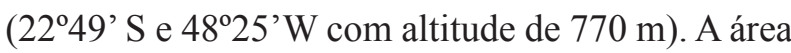
experimental apresentava um Nitossolo Vermelho, de textura argilosa (EMBRAPA, 2006) com as seguintes características fisico-químicas: $420,0 \mathrm{~g}$ $\mathrm{kg}^{-1}$ de argila, 21,0 $\mathrm{g} \mathrm{dm}^{-3}$ de matéria orgânica; $\mathrm{pH}$ 
(CaCl) 5,8; 53,0 $\mathrm{cmol}_{\mathrm{c}} \mathrm{dm}^{-3}$ de $\mathrm{Ca} ; 28,0 \mathrm{cmol}_{\mathrm{c}} \mathrm{dm}^{-3}$ de $\mathrm{Mg} ; 1,0 \mathrm{cmol}_{\mathrm{c}} \mathrm{dm}^{-3}$ de Al; 2,7 $\mathrm{cmol}_{\mathrm{c}} \mathrm{dm}^{-3}$ de $\mathrm{K}$; $33,0 \mathrm{mg} \mathrm{dm}^{-3}$ de $\mathrm{P}$ (resina) e saturação por bases de $74 \%$.

Utilizou-se o delineamento experimental de blocos casualizados em esquema de parcelas subdivididas com quatro repetições. As parcelas foram formadas por quatro densidades de semeadura (30, 50, 70 e 90 plantas por metro). As sub-parcelas foram formadas pela aplicação de reguladores vegetais [controle, $(\mathrm{IBA}+\mathrm{GA}+\mathrm{KT})$, Etil-Trinexapac e $(\mathrm{IBA}+\mathrm{GA}+\mathrm{KT})+$ Etil-Trinexapac], totalizando 64 unidades experimentais. Cada sub-parcela foi formada por 13 linhas de semeadura espaçadas $0,17 \mathrm{~m}$ entre si e com $10 \mathrm{~m}$ de comprimento totalizando $20,4 \mathrm{~m}^{2}$. Foram descartados $1,0 \mathrm{~m} \mathrm{em}$ cada extremidade e três linhas de cada lado da subparcela para se obter uma parcela útil de $9,18 \mathrm{~m}^{2}$.
O experimento foi implantado em sistema de semeadura direta, sendo que o cultivar de trigo utilizado foi o IAC 370, cedido pelo Instituto Agronômico de Campinas (IAC), que apresenta porte médio e boa adaptabilidade para as condições regionais de cultivo, conforme zoneamento agrícola (EMBRAPA, 2010). A adubação de base foi realizada com $160 \mathrm{~kg} \mathrm{ha}^{-1}$ do adubo formulado 0828-16 (NPK). A adubação de cobertura foi realizada com $45 \mathrm{~kg} \mathrm{ha}^{-1}$ de nitrogênio (sulfato de amônio) e $30 \mathrm{~kg} \mathrm{ha}^{-1}$ de potássio $(\mathrm{KCl})$ aplicados no início da fase de perfilhamento da cultura e $45 \mathrm{~kg} \mathrm{ha}^{-1}$ de nitrogênio (sulfato de amônio) no final da fase de perfilhamento, que corresponderam aos estádios $2 \mathrm{e}$ 5 da escala de Feeks (Large, 1954). O somatório do acumulado de chuvas e da lâmina total de irrigação durante o ciclo da cultura foi de $315 \mathrm{~mm}$ (Figura 1), considerado um ótimo valor para as exigências da cultura (EMBRAPA, 2010).

Figura 1. Distribuição de chuvas e lâminas de irrigação durante o ciclo da cultura do trigo (IAC 370).

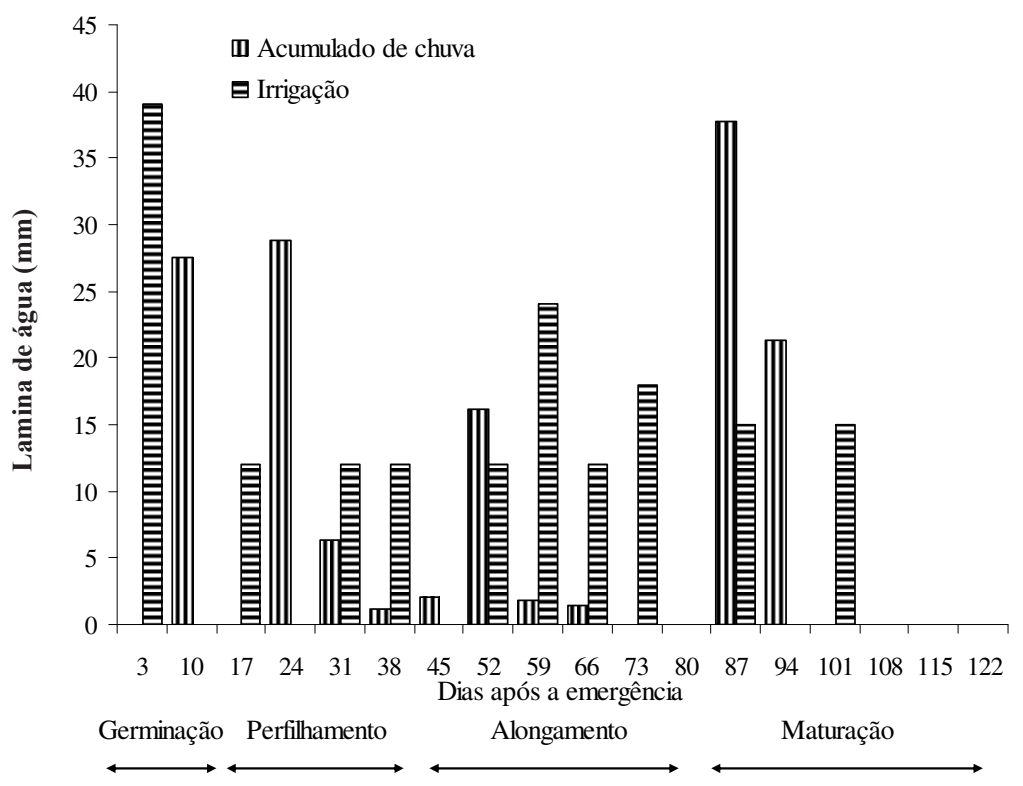

Fonte: Elaboração dos autores.

A aplicação do regulador vegetal $\mathrm{Ax}+\mathrm{GA}+\mathrm{CK}$ foi realizada no início da fase de perfilhamento, na dose de $500 \mathrm{~mL} \mathrm{ha}{ }^{-1}$ (p.c.) enquanto o Etil-
Trinexapac foi aplicado na dose de $400 \mathrm{~mL} \mathrm{ha}^{-1}$ (p.c.) na fase do primeiro nó visível do colmo principal que corresponderam aos estádios 2 e 6 da 
escala de Feeks (LARGE, 1954), respectivamente. Foram utilizados os produtos comerciais Stimulate ${ }^{\circledR}$ (0,005\% de acido indolilbutírico, 0,005\% de ácido giberélico e $0,009 \%$ de cinetina) e Moddus ${ }^{\circledR}$ (250 $\mathrm{g} \mathrm{L}^{-1}$ de Etil-Trinexapac). Os reguladores foram aplicados via pulverização foliar utilizando-se pulverizador de barras pressurizado com $\mathrm{CO}_{2} \mathrm{e}$ pontas tipo leque (110-02), ajustado para um volume de calda de $150 \mathrm{~L} \mathrm{ha}^{-1}$.

O acúmulo de matéria seca foi determinado no final da fase de perfilhamento (42 DAE) e no início do período reprodutivo (antese) (73 DAE) da cultura. Para cada época determinou-se o número de perfilhos por planta e por metro quadrado, a massa de matéria seca de folhas e do colmo. A altura de plantas foi determinada durante toda a fase de alongamento da cultura, (60 aos 88 DAE), com intervalos de quatro dias, sendo os valores definidos como a distância entre a superfície do solo e a porção distal do colmo ou das espigas (quando presentes). A distância entre fonte e dreno foi definida no colmo principal de 15 plantas por parcela, no início da fase de maturação da cultura (120 DAE), através do somatório do comprimento da bainha da folha-bandeira (CB) e a distância entre o nó da folha bandeira e a inserção da espiga (NE).

A assimilação de carbono $(A)$ e transpiração $(E)$ foram medidas aos 3, 7 e 11 dias após a emissão da folha bandeira, entre $9 \mathrm{~h} 00$ e $11 \mathrm{~h} 00$, utilizando-se o aparelho portátil de fotossíntese, Infra Red Gas Analyzer (IRGA, Li-6200, Licor Ltda., Lincoln, $\mathrm{NE}$ ). As características morfológicas da folha bandeira foram determinadas em 15 folhas do colmo principal de cada parcela, onde foram definidos o comprimento, a área foliar e a massa de matéria seca de folhas e, em seguida calculou-se a largura média de folhas.

Os componentes da produção foram determinados na fase de maturação da cultura. Determinou-se o número de espigas por metro quadrado, espiguetas por espiga, número de grãos por espigueta, número de grãos por espiga e massa de grãos por espiga. Após a colheita da parcela útil determinou-se a produtividade $\left(\mathrm{kg} \mathrm{ha}^{-1}\right)$ corrigida para $13 \%$ de umidade, o peso hectolítrico $(\mathrm{PH})$ e a massa de 1000 grãos.

Os resultados foram submetidos a análise de variância pelo teste $\mathrm{F}(\mathrm{p}<0,05)$ e quando detectadas variações significativas as médias foram contrastadas pela análise de regressão para as densidades de semeaduras e pelo teste de Tukey ( $p$ $<0,05)$ para os reguladores vegetais.

\section{Resultados e Discussão}

A competição entre plantas provocada pelo aumento da densidade de cultivo resultou em redução no acúmulo de matéria seca de plantas no final da fase de perfilhamento e na fase de antese (Figura 2). O maior acúmulo de matéria seca observado em plantas cultivadas nas menores densidades reflete o elevado número de perfilhos emitidos, quando comparadas com as maiores densidades de semeadura, onde a emissão (Figura 3a) e a sobrevivência (Figura 3b) de perfilhos foram drasticamente reduzidas pela competição entre plantas. Cada perfilho emitido, constituído de colmo e folhas próprios, participa ativamente do processo de assimilação e acúmulo de matéria seca com potencial de emitir ainda novos perfilhos, de acordo com as condições de do ambiente de cultivo. O controle da emissão de perfilhos ocorre pelo balanço hormonal da planta, sendo afetado, entre outros fatores, pela qualidade de luz incidente, reflexo da competição entre plantas (BALLARÉ et al., 1992; ALMEIDA; MUNDSTOCK, 2001). Para se tornar produtivo, um perfilho necessita apresentar taxas de crescimento próximas ao do colmo principal (WOBETO, 1994), caso contrário a probabilidade de abortamento aumenta, principalmente em condições de estresse ambiental (ELHANI et al., 2007). 
Figura 2. Acúmulo de matéria seca de colmos $(a, d)$, folhas $(b, e)$, matéria seca total por planta $(c, f)$ na fase final de perfilhamento e antese, respectivamente, em densidades crescentes de plantas de trigo (IAC 370). **Significativo (p $<0,01)$.
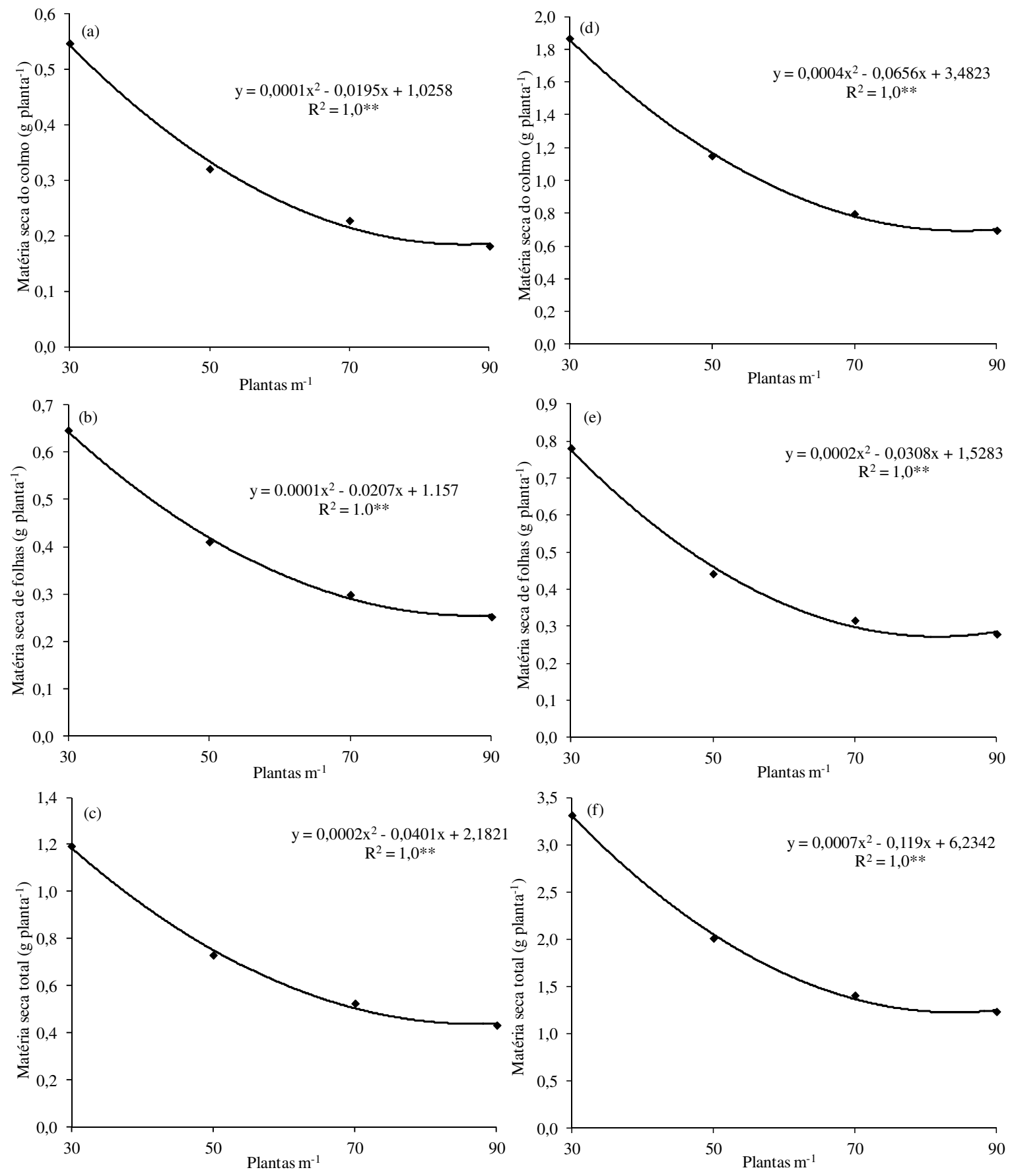

Fonte: Elaboração dos autores.

Aaplicaçãodosreguladores vegetaisnão interferiu na emissão de perfilhos e no acúmulo de matéria seca em plantas de trigo. É importante ressaltar que até o final da fase de perfilhamento apenas o tratamento $\mathrm{IBA}+\mathrm{GA}+\mathrm{KT}$ havia sido aplicado, com o objetivo de estimular o perfilhamento, principalmente nas maiores densidades de cultivo, resultado não observado. O início do alongamento 
em plantas de trigo é observado primeiramente no colmo principal, e em seguida nos perfilhos. Era esperado que aplicação de Etil-Trinexapac pudesse resultar em maior efeito nesta parte da planta, inibindo seu alongamento de forma mais efetiva, permitindo um maior desenvolvimento e acúmulo de matéria seca em perfilhos, resultando em maior sobrevivência dessas estruturas. Este resultado, contudo, não foi observado, levantando a necessidade de novos estudos sobre a relação o desenvolvimento do colmo principal e perfilhos, para que a manipulação desta fase de crescimento da planta possa ser utilizada como prática de cultivo a favor do aumento da produtividade da cultura.
Apesar da redução no acúmulo de matéria seca em plantas cultivadas em altas densidades, o acúmulo total de matéria seca por unidade de área não sofreu alteração. Esses resultados revelam uma elevada plasticidade no desenvolvimento de plantas de trigo em condição de baixa densidade de semeadura, onde a disponibilidade de fatores do meio (água, luz e nutrientes) é maior. A emissão de perfilhos (Figura 3) resultou em maior acúmulo de matéria seca individual de plantas (Figura 2) atuando como mecanismo de compensação para o menor número de plantas por unidade de área. Valério et al. (2009) relatam que a capacidade da cultura do trigo em compensar a redução do número de plantas através da emissão de perfilhos e acúmulo de assimilados nessas estruturas é altamente variável em função do potencial do genótipo em produzir perfilhos.

Figura 3. Número de perfilhos por metro quadrado no final da fase de perfilhamento (a) e na antese (b) em densidades crescentes de plantas de trigo (IAC 370). **Significativo $(\mathrm{p}<0,01)$.

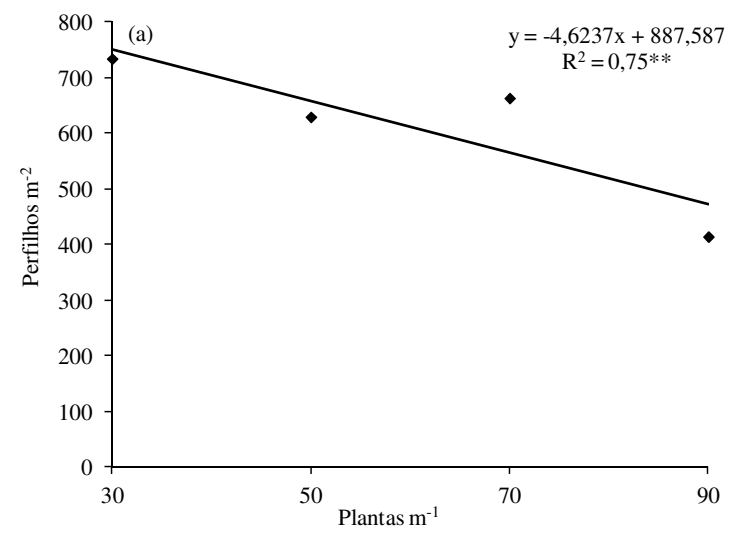

Fonte: Elaboração dos autores.

A densidade de plantas não afetou o crescimento em altura de plantas de trigo em nenhuma das épocas de avaliação. O efeito da aplicação de reguladores vegetais foi verificado a partir do oitavo dia após o início da fase de alongamento da cultura (68 DAE) até a definição da altura final de plantas (88 DAE) (Figura 4). A fase de alongamento na cultura do trigo é marcada por um pico de crescimento em altura em resposta ao aumento da atividade biológica de giberelina (GA) nos meristemas

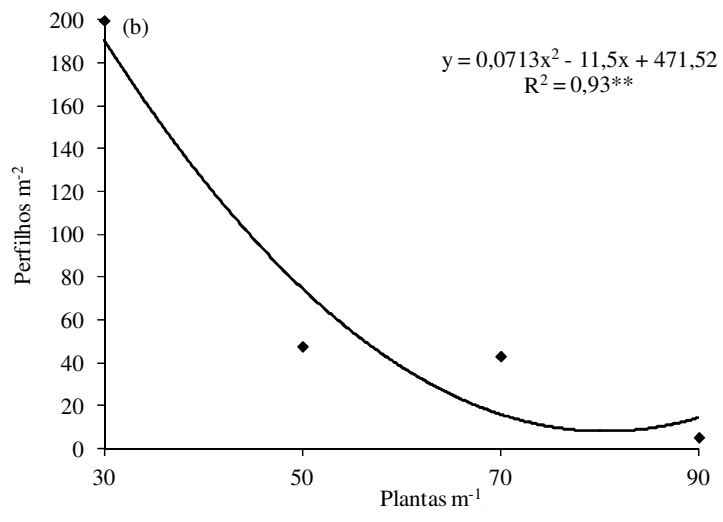

intercalares do colmo (ARTECA, 1995; TAIZ; ZEIGER, 2009), conforme verificado na Figura 4. A eficiência da aplicação de Etil-Trinexapac em inibir a biossíntese de GA ficou evidente a partir do oitavo dia (68 DAE) após o inicio do alongamento e também da sua aplicação nas plantas (60 DAE), sendo que não foram observadas diferenças entre a aplicação de Etil-Trinexapac de maneira isolada ou combinada com IBA $+\mathrm{GA}+\mathrm{KT}$. A diminuição da altura de plantas pela aplicação de Etil-Trinexapac 
também foi observada por ZAGONEL et al. (2002), BERTI, Zagonel e Fernandes (2007) e EsPIndula et al. (2010). No presente estudo, em função das condições climáticas favoráveis, com baixa frequência de chuvas (Figura 1) e de ventos fortes, não houve ocorrência de acamamento de plantas, mesmo em condição de cultivo sem aplicação de Etil-Trinexapac, ou nas maiores densidades de semeadura.

Figura 4. Altura de plantas de trigo (IAC 370) em função da aplicação de IBA $+\mathrm{GA}+\mathrm{KT}$ no inicio do perfilhamento e de Etil-Trinexapac no início da fase de alongamento de plantas. As barras verticais representam os valores de dms $(\mathrm{p}<0,05)$.

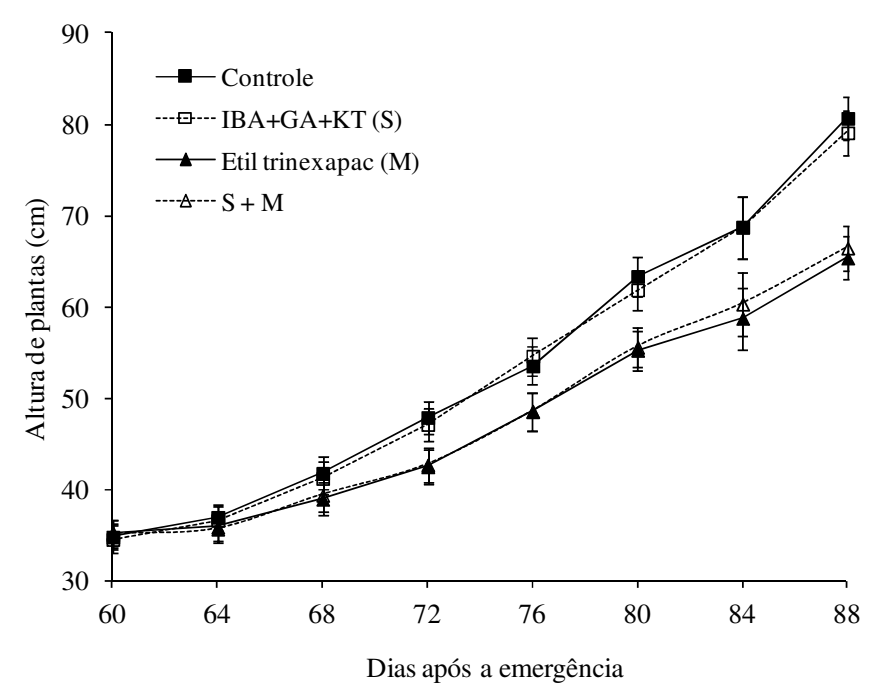

Fonte: Elaboração dos autores.

O acúmulo de matéria seca na folha bandeira foi afetado pela densidade de cultivo (Figura 5), apresentando o mesmo comportamento observado para o acúmulo de matéria seca total de folhas por planta na fase de antese (Figura 2). O desenvolvimento reduzido da folha bandeira pode resultar em prejuízos ao desenvolvimento de grãos, considerando-se que este processo depende basicamente da quantidade de carboidratos acumulados no colmo até a antese e da taxa de assimilação de carbono na fase de pós antese (SIMMONS, 1987). Deve-se ressaltar, contudo, que a área da folha bandeira não foi afetada, portanto a redução no acúmulo de matéria seca destas folhas pode ter ocorrido em função de uma maior taxa de translocação para os grãos em formação, que é a sua função principal.

O efeito prolongado da atividade do EtilTrinexapac pode ser verificado através da morfologia da folha bandeira (Tabela 1). A aplicação de EtilTrinexapac, de maneira isolada ou combinada com $\mathrm{IBA}+\mathrm{GA}+\mathrm{KT}$ provocou diminuição no crescimento em comprimento da folha bandeira, resultando em redução da área foliar e do acúmulo de carboidratos na folha. As giberelinas, juntamente com as auxinas são os hormônios responsáveis pelo alongamento celular que resulta no crescimento das plantas (ARTECA, 1995; TAIZ; ZEIGER, 2009). A inibição da síntese de um desses hormônios, como a GA neste caso, teve efeito direto no crescimento da planta, tanto em altura (Figura 4) quanto na expansão da folha bandeira (Tabela 3). A folha bandeira é considerada como a fonte primária para o enchimento de grãos para a cultura do trigo, devido a curta distância da espiga e o fato dela se manter verde por mais tempo do que as demais folhas da planta, com elevada participação no enchimento de grãos (DOMICIANO et al., 2009). 
Figura 5. Matéria seca da folha bandeira em densidades crescentes de plantas de trigo (IAC 370). **Significativo (p $<0,01)$.

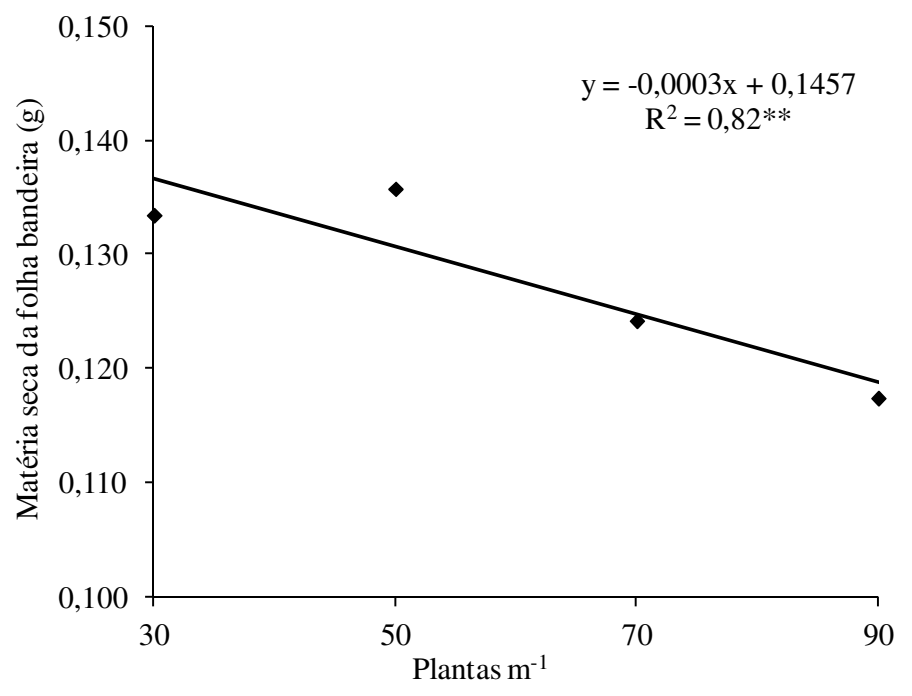

Fonte: Elaboração dos autores.

Tabela 1. Comparação de médias para comprimento, área foliar e massa da matéria seca da folha bandeira de plantas de trigo (IAC 370) em função da aplicação de IBA+GA+KT no inicio do perfilhamento e de Etil-Trinexapac no início da fase de alongamento de plantas.

\begin{tabular}{cccc}
\hline Regulador & Comprimento $(\mathrm{cm})$ & Área foliar $\left(\mathrm{cm}^{2}\right)$ & Matéria seca $\left(\mathrm{g} \mathrm{folha}^{-1}\right)$ \\
\hline Controle & $22,69 \mathrm{a}$ & $25,82 \mathrm{ab}$ & $0,1347 \mathrm{ab}$ \\
$\mathrm{IBA}+\mathrm{GA}+\mathrm{KT}(\mathrm{S})$ & $22,00 \mathrm{a}$ & $26,18 \mathrm{a}$ & $0,1353 \mathrm{a}$ \\
Etil-Trinexapac $(\mathrm{M})$ & $19,39 \mathrm{~b}$ & $23,13 \mathrm{~b}$ & $0,1216 \mathrm{bc}$ \\
$\mathrm{S}+\mathrm{M}$ & $19,83 \mathrm{~b}$ & $22,99 \mathrm{~b}$ & $0,1191 \mathrm{c}$ \\
\hline $\mathrm{dms}$ & 1,44 & 2,81 & 0,013 \\
\hline
\end{tabular}

Médias seguidas da mesma letra, na vertical, não diferem entre si pelo teste de Tukey $(p<0,05)$.

Fonte: Elaboração dos autores.

$\mathrm{O}$ aumento na densidade de cultivo resultou em redução no comprimento da bainha, e da distância entre o último nó e a espiga, que refletiu de maneira direta na distância total de movimento de fotoassimilados entre a folha bandeira (fonte) e os grãos na espiga (dreno) (Figura 6). Mesmo sem haver diferenças significativas para altura de plantas, a variação na quantidade de plantas por unidade de área resultou em alterações morfológicas observadas apenas através de uma avaliação mais detalhada das plantas. Portanto, plantas com altura semelhante podem ser obtidas através do crescimento diferenciado de seus constituintes (entrenós), sendo que plantas cultivadas em elevadas densidades de cultivo apresentam os entrenós inferiores do colmo mais desenvolvidos em detrimento dos entrenós superiores, próximos à espiga. Comportamento contrário pode ser observado, neste caso, nas menores densidades de cultivo. De acordo com Madani et al. (2010), tanto a atividade do dreno, quanto a distância entre este e a fonte tem importância variável em função das condições de cultivo, podendo ser manipuladas em programas de melhoramento genético. 
Figura 6. Comprimento da bainha da folha bandeira (a), distância entre o último nó e a espiga (b) e distância entre fonte e dreno (c) em densidades crescentes de plantas de trigo (IAC 370).**Significativo $(\mathrm{p}<0,01)$.
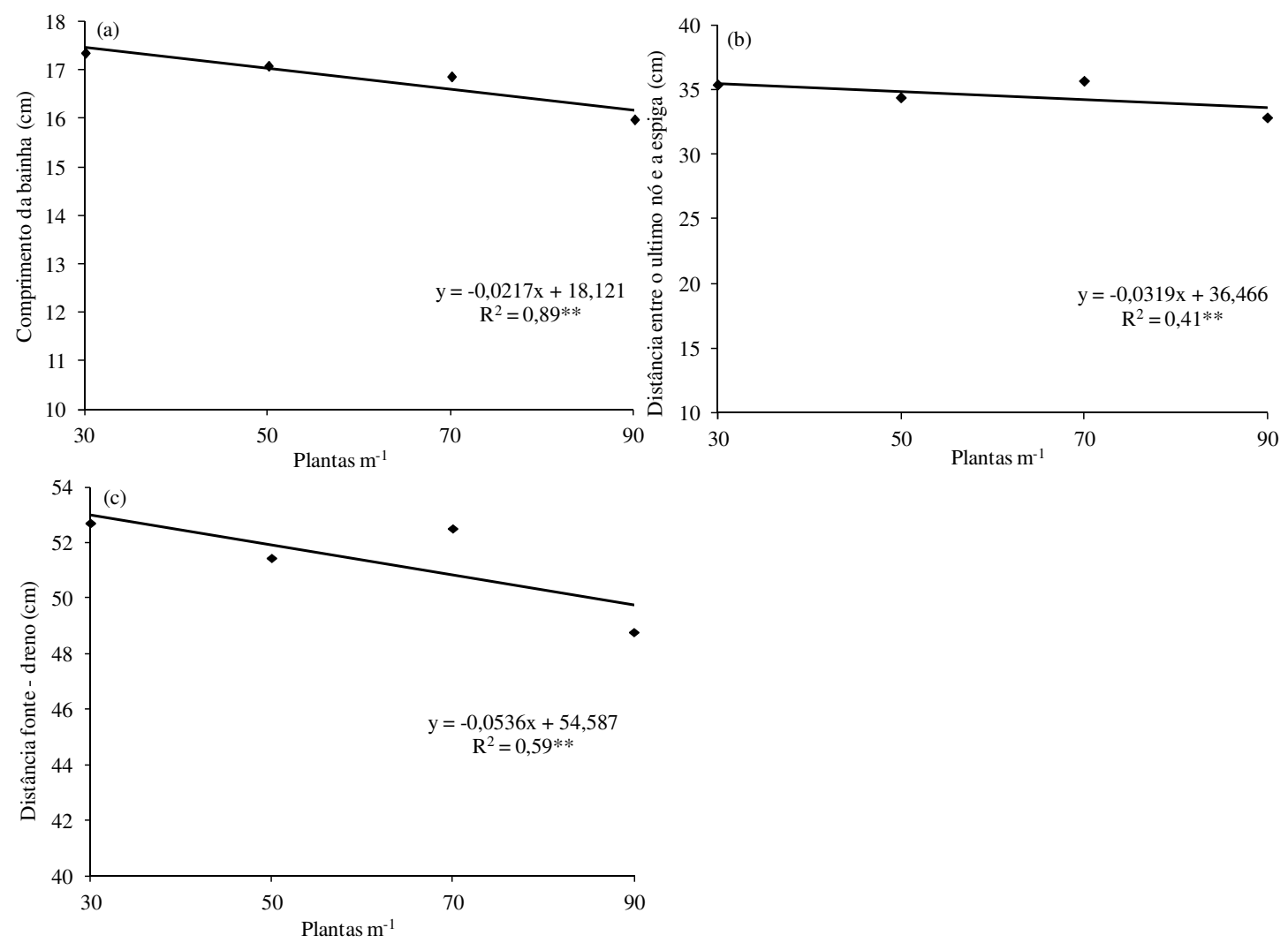

Fonte: Elaboração dos autores.

A aplicação de Etil-Trinexapac, de maneira isolada ou associada à aplicação de IBA+GA+KT na fase de perfilhamento, resultou em decréscimo acentuado da distância entre fonte e dreno em plantas de trigo (Tabela 2). O encurtamento da distância entre a folha bandeira e a espiga está mais associado com a redução do crescimento do último entrenó do colmo do que com o comprimento da bainha da folha, onde o efeito do regulador foi menos expressivo, apesar de significativo. Podese ressaltar, portanto, o prolongamento do efeito da inibição da biossíntese de GA provocado pela aplicação de Etil-Trinexapac na fase de alongamento dos primeiros entrenós da planta, o qual interferiu de maneira significativa no desenvolvimento do ultimo entrenó das plantas e da folha bandeira, conforme demonstrado anteriormente. $\mathrm{O}$ transporte de açúcares pelo floema pode ocorrer entre órgãos distantes, mas normalmente um dreno é suprido de fotoassimilados pelas fontes próximas e, as relações fonte/dreno da planta, são continuamente modificadas com o desenvolvimento do vegetal (PIMENTEL, 1998). Considerando-se que o transporte de carboidratos entre a fonte e o dreno envolve uma série de processos metabólicos ativos e passivos, o encurtamento da distância entre a folha e a espiga em plantas de trigo pode resultar em aumento da taxa de translocação de assimilados, com reflexos significativos na produtividade de grãos, principalmente em condições de baixa disponibilidade hídrica. 
Tabela 2. Comparação de médias para o comprimento da bainha da folha bandeira (CB), distância entre o último nó e a espiga (DNF) e a distância entre fonte e dreno (DFD) em função da aplicação IBA+GA+KT no inicio do perfilhamento e de Etil-Trinexapac no início da fase de alongamento de plantas de trigo (IAC 370).

\begin{tabular}{cccc}
\hline Regulador & CB $(\mathrm{cm})$ & DNF $(\mathrm{cm})$ & DFD $(\mathrm{cm})$ \\
\hline Controle & $17,49 \mathrm{a}$ & $36,98 \mathrm{a}$ & $54,47 \mathrm{a}$ \\
IBA+GA+KT (S) & $17,56 \mathrm{a}$ & $37,61 \mathrm{a}$ & $55,17 \mathrm{a}$ \\
Etil-Trinexapac (M) & $16,05 \mathrm{~b}$ & $31,37 \mathrm{~b}$ & $47,42 \mathrm{~b}$ \\
S + M & $16,19 \mathrm{~b}$ & $32,25 \mathrm{~b}$ & $48,43 \mathrm{~b}$ \\
\hline dms & 0,61 & 2,81 & 3,17 \\
\hline
\end{tabular}

Médias seguidas da mesma letra, na vertical, não diferem entre si pelo teste de Tukey $(p<0,05)$.

Fonte: Elaboração dos autores.

A assimilação de carbono aumentou de maneira significativa em função do aumento na densidade de semeadura (Figura 7). Os maiores valores de assimilação de carbono foram observados para as densidades de 70 plantas por metro aos 3 (Figura 7a) e 7 (Figura 7b) dias após a emissão da folha bandeira e para a densidade de 90 plantas por metro aos 11 dias após a emissão (Figura 7c). Este comportamento pode estar associado ao acúmulo de matéria seca por planta na fase de antese e ao menor desenvolvimento de folhas para as maiores densidades de cultivo, sendo que as duas características se complementam em proporções variadas para a definição da produtividade final da cultura (ASSENG; VAN HERWAARDEN, 2003). Portanto, plantas que apresentam acúmulo de assimilados pouco satisfatório até o início da antese podem investir em maiores taxas de assimilação no período pós antese para manter o potencial produtivo. As taxas de transpiração apresentaram comportamento semelhante ao observado para as taxas de assimilação de carbono (Figura 7d, 7e e 7f), sendo que os maiores valores foram observados para as maiores densidades de semeadura, evidenciando uma maior atividade estomática nessas condições.

A taxa de transpiração da folha bandeira foi afetada de maneira significativa pela aplicação dos reguladores vegetais (Tabela 3). De maneira geral, o controle apresentou as menores taxas de transpiração, em comparação com os demais tratamentos. A aplicação dos reguladores vegetais pode ter resultado em alterações no desenvolvimento de estômatos, em quantidade ou tamanho, ou mesmo no controle da abertura e fechamento estomático, resultando nos maiores valores transpiração. Contudo, considerando-se que as plantas foram submetidas a um controle adequado no suprimento de água durante todo o período de condução do experimento, é possível que a variação nas taxas de transpiração em função da aplicação de reguladores tenha ocorrido em função de alterações morfológicas na folha bandeira.

Mesmo com reduzido número de espigas por metro quadrado (Figura 8), os maiores valores de produtividade foram alcançados nas menores densidades de planta, com decréscimo em função do aumento do número de plantas na linha de cultivo (Figura 9). O efeito negativo do aumento na densidade de plantas nos componentes individuais do rendimento da espiga (Figura 10) ocorreu em resposta ao menor acúmulo de matéria seca por planta, principalmente na fase de antese, em decorrência da intensa competição entre plantas. Rodrigues et al. (2002) observaram que o número de grãos por metro quadrado está altamente relacionado à capacidade da planta em acumular biomassa e transferi-la às estruturas reprodutivas em pré-antese. A análise de trilha para os componentes da produção da cultura do trigo revela que o acúmulo de biomassa na parte aérea de plantas é um dos principais fatores relacionados ao rendimento de grãos na cultura (OKUYAMA; FEDERIZZI; BARBOSA NETO, 2004), juntamente com o número de espigas por metro quadrado e o número de grãos por espiga. Os valores de $\mathrm{PH}$ não foram afetados pelos tratamentos, apresentando valor médio de $80,91 \mathrm{~kg} 100 \mathrm{~L}^{-1}$. 
Figura 7. Assimilação líquida de carbono (a), (b) e (c) e taxa de transpiração (d) (e) e (f) aos 3, 7 e 11 dias após a emissão da folha bandeira, respectivamente, em densidades crescentes de plantas de trigo (IAC 370). **Significativo $(\mathrm{p}<0,01)$.
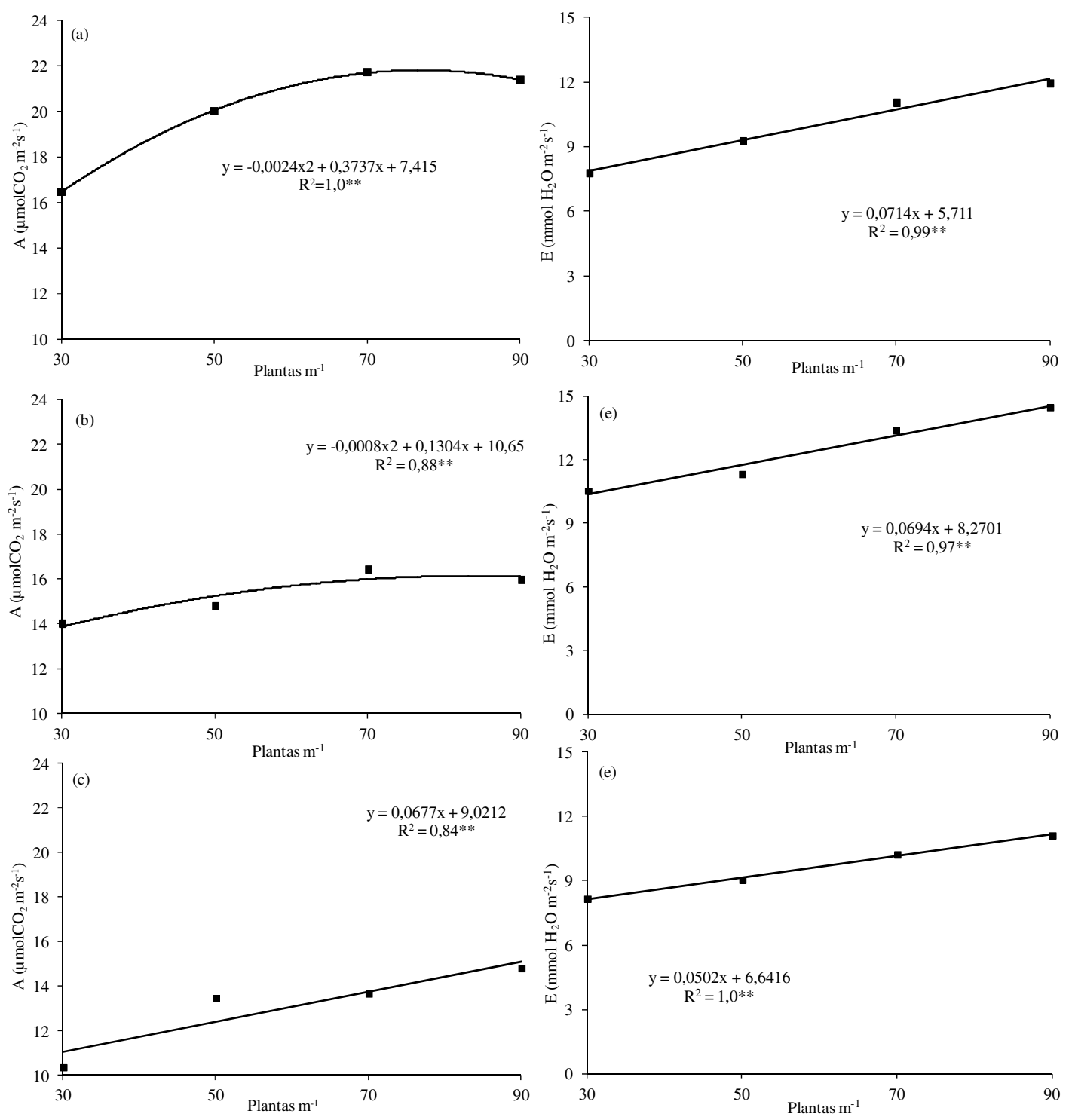

Fonte: Elaboração dos autores 
Tabela 3. Transpiração (E) da folha bandeira de plantas de trigo (IAC 370) em função da em função da aplicação de $\mathrm{IBA}+\mathrm{GA}+\mathrm{KT}$ no inicio do perfilhamento e de Etil-Trinexapac no início da fase de alongamento de plantas.

\begin{tabular}{cccc}
\hline & \multicolumn{3}{c}{$\mathrm{E}\left(\mathrm{mmol} \mathrm{H}_{2} \mathrm{O} \mathrm{m}^{-2} \mathrm{~s}^{-1}\right)$} \\
\hline Regulador & $3 \mathrm{DAE}^{1}$ & $7 \mathrm{DAE}$ & $11 \mathrm{DAE}$ \\
\hline Controle & $9,09 \mathrm{~b}$ & $12,04 \mathrm{a}$ & $8,91 \mathrm{~b}$ \\
IBA+GA+KT (S) & $10,94 \mathrm{a}$ & $13,26 \mathrm{a}$ & $10,25 \mathrm{a}$ \\
Etil-Trinexapac (M) & $10,08 \mathrm{ab}$ & $12,02 \mathrm{a}$ & $9,88 \mathrm{a}$ \\
$\mathrm{S}+\mathrm{M}$ & $9,87 \mathrm{bc}$ & $12,42 \mathrm{a}$ & $9,57 \mathrm{ab}$ \\
\hline $\mathrm{dms}$ & 0,96 & 1,31 & 0,94 \\
\hline
\end{tabular}

Médias seguidas da mesma letra, na vertical, não diferem entre si pelo teste de Tukey $(\mathrm{p}<0,05)$. ${ }^{1} \mathrm{DAE}$ : dias após a emissão da folha bandeira.

Fonte: Elaboração dos autores.

Figura 8. Número de espigas por metro quadrado (a), e incremento no número de espigas (b) em densidades crescentes de plantas de trigo (IAC 370). **Significativo $(\mathrm{p}<0,01)$.
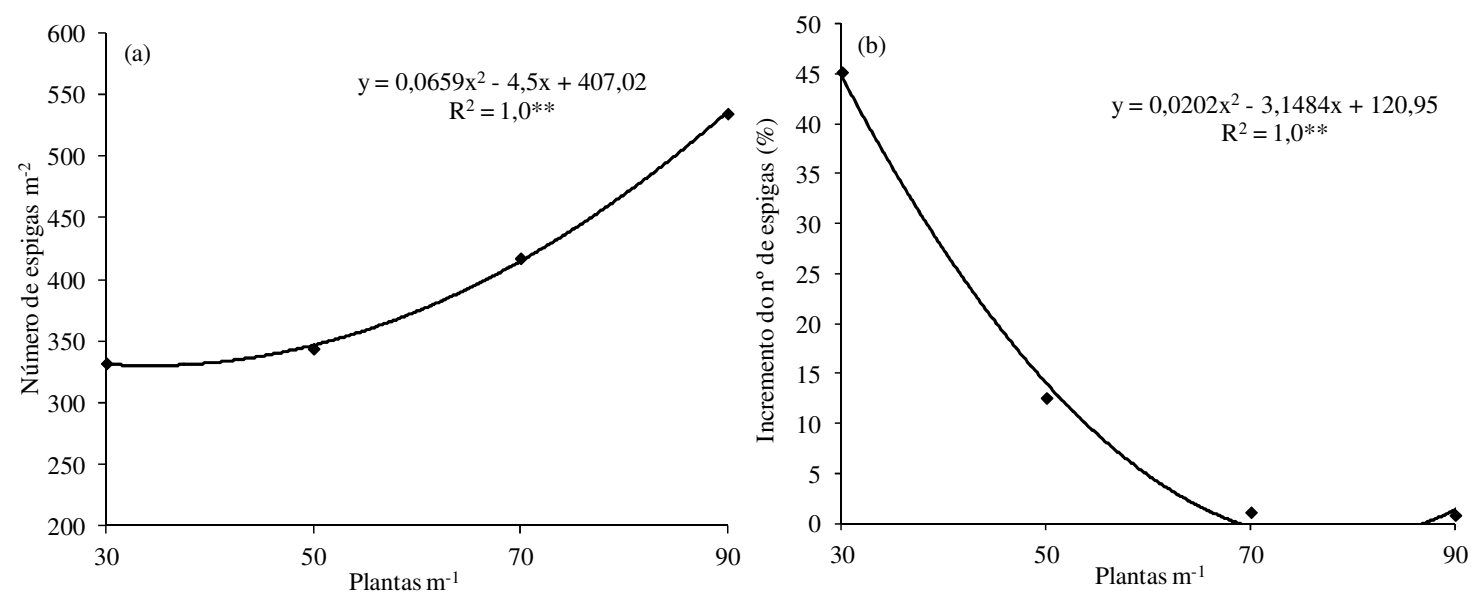

Fonte: Elaboração dos autores.

Figura 9. Produtividade de grãos em densidades crescentes de plantas de trigo (IAC 370). $* *$ Significativo $(\mathrm{p}<0,01)$.

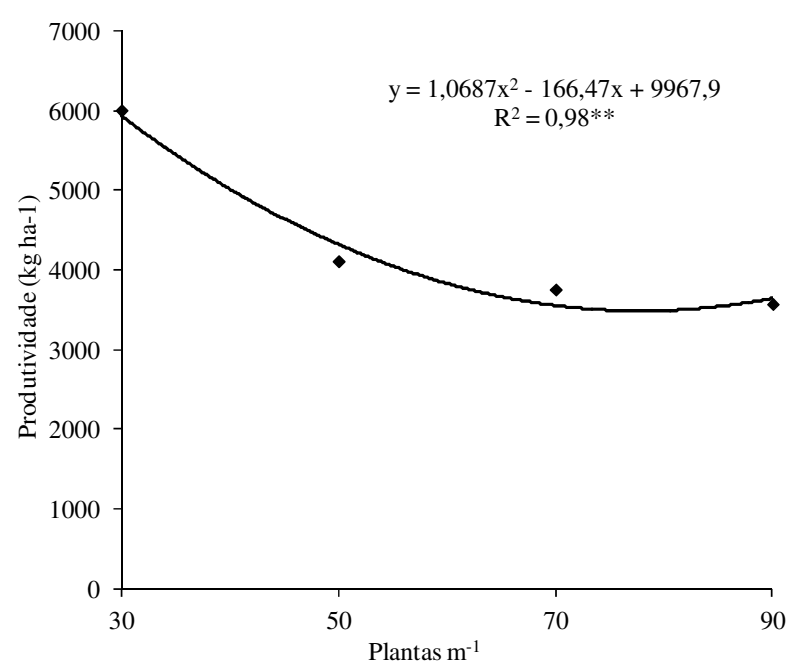

Fonte: Elaboração dos autores. 
Figura 10. Número de grãos (a), número de espiguetas férteis (b), comprimento da ráquis (c) e massa de grãos por espiga (d) em densidades crescentes de plantas de trigo (IAC 370). **Significativo ( $p<0,01)$.
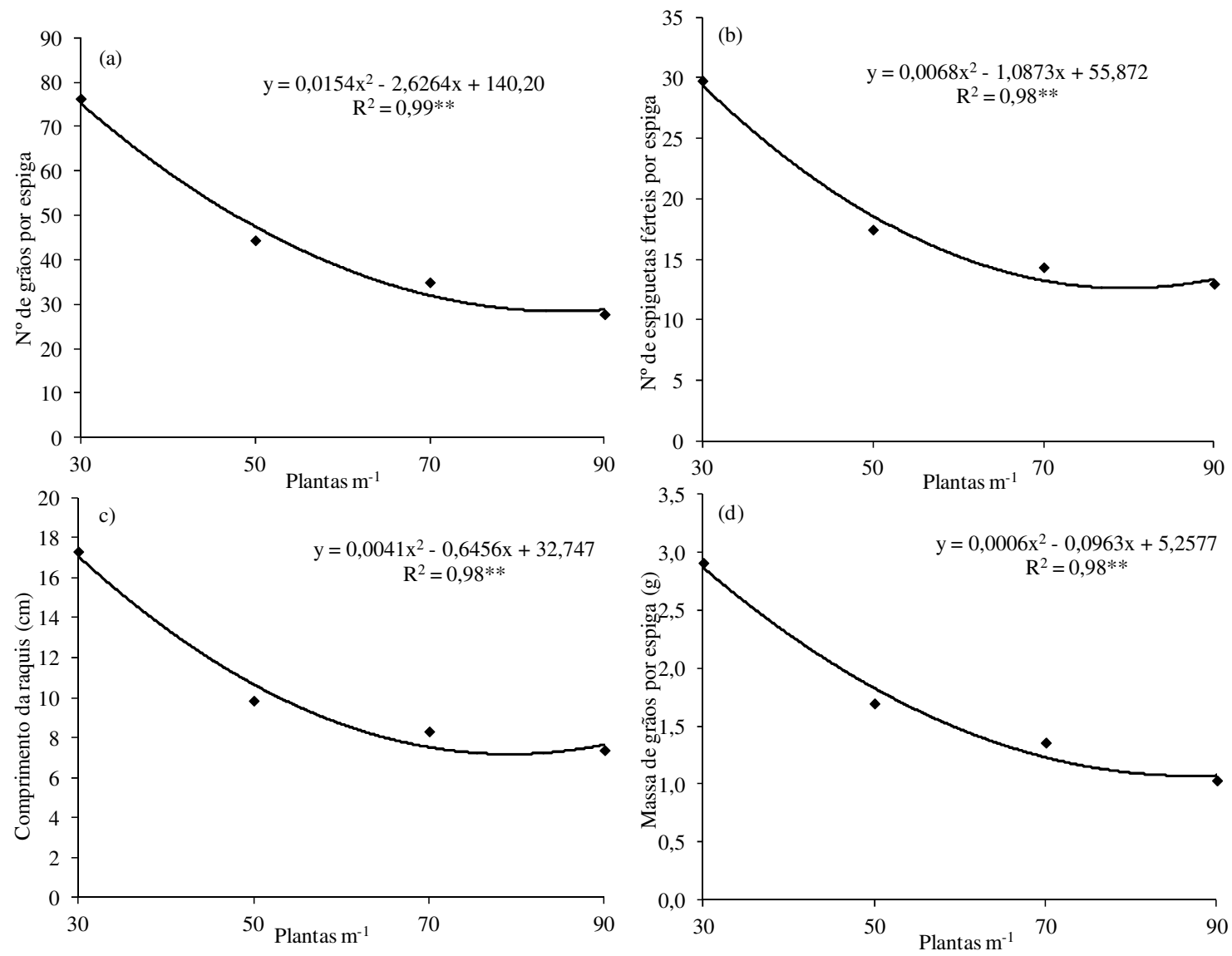

Fonte: Elaboração dos autores.

O acúmulo de matéria seca por planta até a antese (Figura 2) proporcionou o desenvolvimento de plantas mais produtivas nas menores densidades de semeadura, através do aumento no comprimento da raquis, do número de espiguetas e de grãos por espiga, componentes individuais do rendimento. Em contrapartida, o aumento na densidade de cultivo comprometeu o acúmulo de assimilados por planta, as quais, mesmo apresentando maiores taxas de assimilação de carbono na folha bandeira, não conseguiram manter os componentes individuas do rendimento de espigas e mesmo com maior número de espigas por metro quadrado apresentaram produtividade reduzida. Neste caso, o acúmulo de matéria seca na fase de antese parece ter maior importância relativa para a definição da produtividade da cultura, quando comparada com a

assimilação durante a fase de enchimento de grãos, quando o cultivo ocorre na ausência de estresses ambientais. A ocorrência de estresse hídrico na fase de alongamento de plantas ou na fase de enchimento de grãos poderia, contudo proporcionar resultados diferentes, em termos da participação de cada característica na composição do rendimento da cultura.

Mesmo provocando redução em um componente importante para a produção de grãos de trigo, como a massa de mil grãos (Tabela 4), a aplicação de Etil-Trinexapac não resultou em decréscimo na produtividade da cultura. Resultados para massa de mil grãos em plantas de trigo submetidas à aplicação de reguladores vegetais têm se mostrado bastante controversos, podendo apresentar aumento (ZAGONEL et al., 2002), redução (ESPINDULA 
et al., 2010) ou mesmo comportamento variado em função do material genético utilizado (ZAGONEL; FERNANDES, 2007). É possível, portanto, que as alterações morfológicas em plantas de trigo tratadas com Etil-Trinexapac possam resultar em efeitos significativos, em termos de produtividade, para materiais genéticos ou mesmo condições ambientais específicas, como uma possível restrição hídrica na fase de enchimento de grãos.

Tabela 4. Comparação de médias para massa de mil grãos em plantas de trigo (IAC 370) em função da aplicação de em função da aplicação de IBA+GA+KT no inicio do perfilhamento e de Etil-Trinexapac no início da fase de alongamento de plantas.

\begin{tabular}{cc}
\hline Regulador & Massa de mil grãos (g) \\
\hline Controle & $43,39 \mathrm{a}$ \\
IBA+GA+KT (S) & $42,80 \mathrm{ab}$ \\
Etil-Trinexapac (M) & $41,12 \mathrm{~b}$ \\
$\mathrm{~S}+\mathrm{M}$ & $41,00 \mathrm{~b}$ \\
\hline $\mathrm{dms}$ & 1,93 \\
\hline
\end{tabular}

Médias seguidas da mesma letra, na vertical, não diferem entre si pelo teste de Tukey $(\mathrm{p}<0,05)$.

Fonte: Elaboração dos autores.

\section{Conclusões}

A aplicação de IBA+GA+KT no início da fase de perfilhamento não afeta os componentes produtivos e a produtividade da cultura do trigo;

A aplicação de Etil-Trinexapac provoca alterações na distância entre fonte e dreno e no desenvolvimento da folha bandeira em plantas de trigo, sem afetar a produtividade de grãos;

A produtividade de grãos de trigo está mais associada ao acúmulo de matéria seca em pré antese do que com a taxa de assimilação de $\mathrm{CO}_{2}$ pós antese em densidades crescentes de semeadura;

Maiores valores de produtividade na cultura do trigo são observados para as menores densidades de semeadura, pelo incremento do rendimento individual de espigas.

\section{Agradecimentos}

Os Autores agradecem à Fundação de Amparo à Pesquisa do Estado de São Paulo (FAPESP) pelo auxílio financeiro para a realização do projeto.

\section{Referências}

ALMEIDA, M. L.; MUNDSTOCK, C. M. A qualidade da luz afeta o afilhamento em plantas de trigo, quando cultivadas sob competição. Ciência Rural, Santa Maria, v. 31, n. 3, p. 401-408, 2001.

ARTECA, R. N. Plant growth substances: principles and applications. New York: Champman \& Hall, 1995. 332 p.

ASSENG, S.; VAN HERWAARDEN, A. F. Analysis of the benefits to wheat yield from assimilates stored prior to grain filling in a range of environments. Plant and Soil, The Hague, v. 256, n. 1, p. 217-229, 2003.

BALLARÉ, C. L.; SCOPEL, A. L.; SANCHEZ, R. A.; RADOSEVICH, S. R. Photomorphogenic processes in the agricultural environment. Photochemistry and Photobiology, Hoboken, v. 56, n. 5, p. 777-788, 1992.

BERTI, M.; ZAGONEL, J.; FERNANDES, E. C. Produtividade de cultivares de trigo em função do trinexapac ethyl e doses de nitrogênio. Scientia Agrícola, Piracicaba, v. 8, n. 1, p. 127-134, 2007.

CRUZ, P. J.; CARVALHO, F. I. F.; CAETANO, V. R.; SILVA, S. A.; KUREK, A. J.; BARBIERI, R. L. Caracteres relacionados com a resistência ao acamamento em trigo comum. Ciência Rural, Santa Maria, v. 31, n. 4, p. 563-568, 2001.

CRUZ, P. J.; CARVALHO, F. I. F.; SILVA, S. A.; KUREK, A. J.; BARBIERI, R. L.; CARGNIN, A. Influência do acamamento sobre o rendimento de grãos e outros caracteres em trigo. Revista Brasileira de Agrociências, Pelotas, v. 9, n. 1, p. 5-8, 2003. 
DOMICIANO, G. P.; RESENDE, R. S.; RODRIGUES, F. A.; DAMATTA, F. M. Alterações na fotossíntese de plantas infectadas por fitopatógenos. Revisão Anual de Patologia de Plantas, Passo Fundo, v. 17, n. 1, p. 305339, 2009.

ELHANI, S.; MARTOS, V.; RHARRABTI, Y.; C. ROYO, C.; GARCÍA Del MORA, L. F. Contribution of main stem and tillers to durum wheat (Triticum turgidum L. var. durum) grain yield and its components grown in Mediterranean environments. Field Crops Research, Amsterdam, v. 103, n. 1, p. 25-35, 2007.

EMPRESA BRASILEIRA DE PESQUISA AGROPECUÁRIA - EMBRAPA. Centro Nacional de Pesquisa de Solos-CNPS. Sistema brasileiro de classificação de solos. Brasília: EmbrapaSPI; Rio de Janeiro: Embrapa-CNPS, 2006. 306 p.

Centro Nacional de Pesquisa de Trigo. Informações técnicas para trigo e triticale safra 2011. In: REUNIÃO DA COMISSÃO BRASILEIRA DE PESQUISA DE TRIGO E TRITICALE, 4., Cascavel: COODETEC, 2010. 170 p.

ESPINDULA, M. C.; ROCHA, V. S.; SOUZA, L. T.; SOUZA, M. A.; GROSSI, J. A. S. Efeitos de reguladores de crescimento na elongação do colmo de trigo. Acta Scientiarum Agronomy, Maringá, v. 32, n. 1, p. 109-116, 2010.

HOLEN, D. L.; BRUCKNER, P. L.; MARTIN, J. M.; CARLSON, G. R.; WICHMAN, D. M.; BERG, J. E. Response of winter wheat to simulated stand reduction. Agronomy Journal, Madison, v. 93, n. 1, p. 364-370, 2001.

INOUE, T.; INAGA, S.; SUGIMOTO, Y.; EL SIDDIG, $\mathrm{K}$. Contribution of pre-anthesis assimilates and current photosynthesis to grain yield, and their relationships to drought resistance in wheat cultivars grown under different soil moisture. Photosynthetica, Dordrecht, v. 42, n. 1, p. 99-104, 2004.

LARGE, E. C. Growth stages in cereals illustration of the feeks scale. Plant Pathology, New York, v. 3, n. 1, p. 128-129, 1954.

MADANI, A.; RAD, A. S.; PAZOKI, A.; NOURMOHAMMADI, G.; ZARGHAMI, R. Wheat (Triticum aestivum L.) grain filling and dry matter partitioning responses to source:sink modifications under postanthesis water and nitrogen deficiency. Acta Scientiarum. Agronomy, Maringá, v. 32, n. 1, p. 145-151, 2010.
MARTINS. M. B. G.; CASTRO, P. R. C. Efeitos de giberelina e ethephon na anatomia de plantas de canade-açúcar. Pesquisa Agropecuária Brasileira, Brasília, v. 34, n. 10, p. 1855-1863, 1999.

OKUYAMA, L. A.; FERERIZZI, L. C.; BARBOSA NETO, J. F. Correlation and path analysis of yield and its components and plant traits in wheat. Ciência Rural, Santa Maria, v. 34, n. 6, p. 1701-1708, 2004.

OZTURK, A.; CAGLAR, O.; BULUT, S. Growth and yield response of facultative wheat to winter sowing, freezing sowing and spring sowing at different seeding rates. Journal of Agronomy Crop Science, Erzurum, v. 192, n. 1, p. 10-16, 2006.

PIMENTEL, C. Metabolismo do carbono na agricultura tropical. Seropédica: EDUR, 1998. 150 p.

RODRIGUES, O; DIDONET, A. D.; TEIXEIRA, M. C. C.; ROMAN, E. S. Características fisiológicas associadas ao avanço no potencial de rendimento de grãos de trigo. Passo Fundo: Embrapa Trigo, 2002. 26 p.

SIMMONS, R. S. Growth, development, and physiology. In: HEYNE, E. G. (Ed.). Wheat and heat improvement. Madison: Wisconsin, 1987. p. 77-113.

SLEEPER, D. A.; POEHLMAN, J. M. Breeding field crops. Ames: Blackwell Pub Iowa, 2006. 424 p.

TAIZ, L.; ZEIGER, E. Fisiologia vegetal. 4. ed. Porto Alegre: Artmed, 2009.

VALÉRIO, I. P.; CARVALHO, F. I. F.; OLIVEIRA, A. C.; BENIN, G.; SOUZA, V. Q.; MACHADO, A. A.; BERTAN, I.; BUSATO, C. C.; SILVEIRA, G.; FONSECA, D. A. R. Seeding density in wheat genotypes as a function of tillering potential. Scientia Agricola, Piracicaba, v. 66, n. 1, p. 28-39, 2009.

WOBETO, C. Padrão de afilhamento, sobrevivência de afilhos e suas relações com o rendimento de grãos em trigo. 1994. Dissertação (Mestrado em Fitotecnia) Faculdade de Agronomia, Universidade Federal do Rio Grande do Sul, Porto Alegre.

ZAGONEL, J.; FERNANDES, E. C. Doses e épocas de aplicação do regulador de crescimento afetando cultivares de trigo em duas doses de nitrogênio. Planta Daninha, v. 25, n. 2, p. 331-339, 2007.

ZAGONEL J.; VENANCIO, W. S.; KUNZ, R. P.; TANAMATI, P. Doses de nitrogênio e densidades de plantas com e sem regulador de crescimento afetando o trigo, Cultivar OR-1. Ciência Rural, Santa Maria, v. 32, n. 1, p. 25-29, 2002. 
